\title{
DA PARÁFRASE À POLISSEMIA: \\ (IM)POSSIBILIDADES DE LEITURA(S) EM SALA DE AULA
}

\author{
FROM PARAPHRASE TO POLYSEMY: \\ (IM)POSSIBILITIES OF READING(S) IN THE CLASSROOM
}

DE LA PARÁFRASIS A LA POLISEMIA: (IM)POSIBILIDADES DE LECTURA(S) EN EL AULA

\author{
Letícia Moraes Esposto ${ }^{1}$ \\ Filomena Elaine Paiva Assolini ${ }^{2}$
}

Resumo: Este trabalho é o recorte de uma pesquisa que objetivou investigar as condições de produção da alfabetização em escolas públicas estaduais. As análises apontam que a alfabetização se dá em condições de produção onde a leitura é pautada na paráfrase, excluindo as possibilidades polissêmicas.

Palavras-chave: Análise de discurso; alfabetização; leitura.

\begin{abstract}
This work is part of a research that aimed to investigate the conditions of literacy production in state public schools. The analyzes point out that literacy takes place in production conditions where reading is based on paraphrase, excluding polysemic possibilities.
\end{abstract}

Keywords: Discourse Analysis; literacy; reading.

Resumen: Este trabajo es parte de una investigación que tuvo como objetivo investigar las condiciones de producción de alfabetización en las escuelas públicas estatales. Los análisis señalan que la alfabetización se da en condiciones de producción donde la lectura se basa en la paráfrasis, excluyendo las posibilidades polisémicas.

Palabras clave: Análisis del habla; literatura; leyendo.

\section{Introdução}

Este trabalho apresenta o recorte de uma pesquisa maior ${ }^{3}$, que teve como objetivo investigar as condições de produção da alfabetização nos dois primeiros anos do Ensino Fundamental I, em escolas estaduais do interior paulista. Partimos do pressuposto segundo o qual as condições de produção nas quais se desenvolvem as práticas pedagógicas dos professores alfabetizadores influenciam o ensino da leitura e da escrita.

Entendemos que a alfabetização não deve se dar somente enquanto um ato mecânico de leitura e escrita, que visa a apropriação do sistema alfabético, mas sim, como um processo que envolve muitos aspectos, como levar/conduzir o sujeito a ler, escrever, interpretar e apropriarse das funções sociais dessas práticas culturais.

A preocupação com as condições de produção, nas quais se dão as práticas pedagógicas escolares que têm o propósito de ensinar a ler e a escrever, dizem respeito a se essas práticas abrem espaço para a polissemia e criação de sentidos. Durante o processo de alfabetização é muito comum que os professores trabalhem com leituras de diferentes gêneros textuais, porém, o que observamos

\footnotetext{
${ }^{1}$ Universidade de São Paulo - Faculdade de Filosofia, Ciências e Letras de Ribeirão Preto.

${ }^{2}$ Universidade de São Paulo - Faculdade de Filosofia, Ciências e Letras de Ribeirão Preto.

${ }^{3}$ ESPOSTO, L. M. Alfabetização nos anos iniciais do Ensino Fundamental: (des)caminhos da Base Nacional Comum Curricular. Dissertação (Mestrado em Educação) - Faculdade de Filosofia, Ciências e Letras de Ribeirão Preto, Universidade de São Paulo, 2021 (em andamento).
} 
durante a realização da dissertação em andamento, é que essas leituras estão fortemente atreladas ao material didático e à realização de atividades mecânicas de interpretação de texto.

Essa forma de trabalhar com a leitura conduz os alunos à paráfrase, uma vez que há sempre a resposta certa e esperada, afirmada pelo manual do professor. Amparados na Teoria discursiva do letramento (TFOUNI, 1996) e na Análise de Discurso de matriz francesa - AD, (PÊCHEUX, 2014a) entendemos que os sentidos não estão colados às palavras, assim, tornase impossível a existência de uma única resposta correta, uma vez que a interpretação é um movimento único de cada sujeito a depender de sua memória discursiva e seu interdiscurso.

Com isso, destacamos que leitura e interpretação são processos intrinsecamente relacionados, uma vez que não concebemos a leitura apenas como decodificação ou interação (ASSOLINI, 2021). Tendo apresentado a problematização deste estudo, ressaltamos que nos fundamentamos na Análise de Discurso Pecheutiana, campo teórico metodológico que busca compreender o processo de produção de sentidos, a partir de uma materialidade linguístico discursiva, assim como, investiga como um sujeito produz sentidos através de determinadas posições e condições de produção.

A nossa pesquisa ancora-se também nas contribuições da Teoria Discursiva do letramento, tal como postulada por Tfouni (1996, 2005), e seguidores, como Assolini (2003, 2016, 2020). A Teoria Discursiva do letramento entende que o letramento é um processo sóciohistórico que se insere em um continuum, com isso, consideramos que há letramento(s) sem alfabetização, pois, a ideia de um continuum permite-nos falar em graus ou níveis de letramento.

Buscando refletir sobre as possibilidades de leitura, analisamos neste artigo alguns recortes de entrevistas com professores alfabetizadores, onde eles contam como se dão as práticas pedagógicas em suas salas de aula. As análises se pautaram nos pressupostos da AD e na teoria discursiva do letramento.

\section{Tessitura teórica: análise de discurso}

Quando tratamos da Análise de Discurso (AD), teoria na qual nos filiamos teórica e metodologicamente, fazemos menção a um campo de estudos que nasceu na França, sendo seu marco inicial a publicação de Michel Pêcheux "Análise Automática do Discurso" em 1969. Apoiada na tríade basilar - psicanálise, marxismo e linguística - Gregolin (2005, p. 103) afirma que esse campo de estudos criou "[...] um efeito subversivo, que trazia a promessa de uma revolução cultural, na medida em que colocava em causa as evidências da ordem humana".

Com isso, inaugura-se uma teoria que rompe com o esquema elementar de comunicação onde o emissor transmite uma mensagem para o receptor, e essa mensagem é entregue e compreendida pelo receptor, tal como foi gerada pelo emissor. De acordo com Pêcheux (2014b, p. 81) o discurso é definido como "efeito de sentidos entre interlocutores"; diante disso, não tratamos apenas de transmissão de informações, mas sim de um complexo processo de produção de sentidos (ORLANDI, 2009).

Cabe ressaltar que para a $\mathrm{AD}$, esse efeito de sentidos ocorre entre sujeitos que são constituídos pelo desejo e marcados pela heterogeneidade (FERNANDES, 2008). São ainda, cindidos - ou seja, assumem várias posições no discurso - e também clivados, isto é, um sujeito fragmentado, uma vez que o inconsciente é constitutivo deste. Essas estruturas, segundo Pêcheux (2014a, p. 139), ideologia e inconsciente, possuem traços comuns uma vez que são capazes de "dissimular sua própria existência no interior do seu funcionamento".

Orlandi (2007, p. 65) afirma que outra característica da ideologia é que ela se dá “[...] não como um conteúdo ' $x$ ', mas o mecanismo de produzi-lo". Dessa forma, outro conceito fundamental para compreendermos o processo de constituição de um discurso é o de formação ideológica 
[...] que constitui um conjunto complexo de atividades e representações que não são nem individuais nem universais, mas se reportam mais ou menos diretamente às posições de classe em conflito umas com as outras. Dessas Formações Ideológicas, fazem parte, enquanto componentes, uma ou mais Formações Discursivas interligadas (HAROCHE, 1971 apud ORLANDI, 2011, p. 27).

Segundo Pêcheux (2014a), as formações ideológicas são representadas na linguagem através das formações discursivas, que dizem respeito ao que pode ser pensado e dito, em determinadas circunstâncias. Em outras palavras, as formações discursivas são "[...] aquilo que numa formação ideológica dada - ou seja, a partir de uma posição dada em uma conjuntura sócio-histórica dada - determina o que pode e deve ser dito" (ORLANDI, 2009, p. 43).

Pêcheux (2014a) afirma que as formações discursivas não são blocos homogêneos, acabados e fechados, mas sim, caracterizam-se pelas contradições e suas circunstâncias heterogêneas. De acordo com Assolini (2015, p. 70), “[...] uma formação discursiva, que é o lugar da constituição do sentido (sua matriz), está em constante movimento e ininterrupta (trans)formação, (re)produzindo-se por meio do interdiscurso".

Dessa forma, o discurso e os sentidos não podem ser neutros, pois estes sofrem influências diretas da ideologia e do contexto sócio histórico de determinado sujeito. Outro ponto importante para nossas análises é que consideramos o trabalho com a língua como um processo heterogêneo, singular e opaco em que os sentidos não são unívocos ou estáveis. Para Orlandi (2001) "ler é saber que o sentido pode ser outro", contudo, na escola vemos que ler é um exercício de colar o sentido às palavras do texto, evocando-nos o trabalho com a ilusão de número 2 de Pêcheux (2014b).

\section{O ensino de leitura no processo de alfabetização}

O processo de alfabetização, no Brasil, geralmente acontece nos anos iniciais do Ensino Fundamental. Entendemos que esse processo vai além de ensinar as práticas de leitura e escrita, pois, o sujeito alfabetizado, além de codificar e decodificar palavras, frases e textos, interpreta, considerando que sua interpretação é uma dentre as muitas possíveis. Com isso, a alfabetização possibilita ao sujeito desenvolver um olhar crítico sobre o funcionamento ideológico da linguagem, conseguindo perceber que os sentidos nem sempre se constroem de maneira óbvia e natural.

Uma de suas características é a incompletude, já que se trata de um processo individual. De acordo com a teoria discursiva do letramento, esse processo não se finda, uma vez que a sociedade está em constante mudança e transformação, exigindo-nos e demandando-nos novos saberes, competências e habilidades.

Muito além de aprender a ler e escrever, a alfabetização contém uma dimensão política e social que pode transformar a visão de mundo dos sujeitos. Conforme a concepção de alfabetizar-letrando, no processo de alfabetização

É fundamental que mostremos aos alunos a finalidade da escrita, bem como a utilidade social e prática da leitura e da escrita. A escrita não deveria ser trabalhada senão a partir de práticas discursivas que possibilitem ao educando entendê-la e olhá-la como um mediador entre ele, o mundo e o outro (ASSOLINI, 2008, p. 136).

Isso posto, vemos que a abordagem discursiva do letramento considera a leitura e a escrita como prática social, ou seja, essas aprendizagens vão muito além dos moldes escolares. Pensar nas práticas de leitura e escrita escolares por meio da $\mathrm{AD}$, implica considerar que estas estão imersas nas relações de poder e malhas da ideologia. Assim, muitas vezes essas práticas “[...] são utilizadas como 
instrumentos de controle empregados sistematicamente pelos setores dominantes para manter o sujeito submetido às zonas de sentido institucionalmente cristalizadas" (ASSOLINI, 2008, p. 137).

A partir dessas ideias, Tfouni, Pereira e Assolini, (2018, p. 17) consideram que, quando tratamos o processo de alfabetização sem considerar o letramento, há uma redução das práticas de leitura e escrita a "[...] um mero ato automático de codificação/decodificação de sinais gráficos, e esse 'aprendizado' não produz resultados nem faz diferença no cotidiano dos sujeitos, visto que não os torna letrados". Portanto, é importante que a escola trabalhe a utilidade prática e social da alfabetização, pois é através dela que os alunos compreendem:

a condição própria da linguagem e de suas diversas formas e a incompletude. Assim, o texto não se apresenta como algo "intocável" que está ali para ser "decodificado" ou "traduzido" mas como ponto de partida para a criação, para a produção de sentidos, para a descoberta de novos sentidos (FERNANDES, 2018, p. 39).

Com isso, torna-se essencial que os professores alfabetizadores trabalhem com a polissemia. De acordo com Orlandi (2011), a polissemia é a possibilidade de criar múltiplos sentidos sobre uma mesma enunciação; já a paráfrase é a instituição da regra, da lei, onde vigora somente um sentido único. Um trabalho pautado na teoria discursiva do letramento possibilita aos alunos criarem diferentes possibilidades de leitura nas salas de aula, que levem em conta a sua subjetividade, para que assim, a interpretação não fique presa em espaços restritos e pré-direcionados.

\section{Metodologia}

Como esclarecido anteriormente, as análises aqui apresentadas foram constituídas com base na AD. Nosso corpus é composto por recortes de entrevistas semiestruturadas realizadas com professores alfabetizadores que lecionam nos dois primeiros anos do Ensino Fundamental I, na rede estadual paulista de ensino.

Segundo Orlandi (2011) “[...] a operacionalização de conceitos na AD não poderá ter a rigidez de outros domínios da linguística, ou seja, lidar-se-á com instruções e não procedimentos estritos, com regularidades e não regras" (2011, p. 178, grifos originais). Sendo assim, a metodologia para a $\mathrm{AD}$, se estabelece num movimento contínuo entre teoria e a própria análise, em um ir e vir constante entre o corpus e os fundamentos. A respeito do analista de discurso, podemos dizer que este

[...] não só procura compreender como o texto produz sentidos; ele procura determinar que gestos de interpretação trabalham aquela discursividade que é objeto de sua compreensão, buscando distinguir que gestos de interpretação estão constituindo os sentidos (e os sujeitos em suas posições) (ASSOLINI, 2003, p. 28).

Ao iniciar as análises discursivas selecionamos recortes que, de acordo com a $\mathrm{AD}$, são entendidos como "[...] fragmentos correlacionados de linguagem e situação" (ORLANDI, 2011, p. 139). Após selecionados os recortes nos detemos nas sequências discursivas de referência (SDR), "enquanto manifestação da realização de um intradiscurso - como ponto de referência a partir do qual o conjunto de elementos do corpus receberá sua organização" (COURTINE, 2016, p. 25).

Depois de selecionados os recortes e as Sequências Discursivas de Referência - SDR (COURTINE, 1982), relacionamos as sequências discursivas e as circunstâncias enunciativas - que são atribuíveis (referenciáveis) aos lugares dentro dos aparelhos ideológicos de uma determinada conjuntura histórica (COURTINE, 2016). 
É necessário assinalar que a AD trabalha com o paradigma indiciário, inaugurado por Carlo Ginzburg (1989). O paradigma proposto pelo pesquisador nos ensina a considerar e valorizar também os indícios e vestígios que podem parecer insignificantes à primeira vista. Ressaltamos que as pesquisas desenvolvidas a partir desta perspectiva de investigação partem de indícios e dados aparentemente negligenciáveis, buscando realidades que escapam à pesquisa experimental dos métodos positivistas (PAULA; TFOUNI, 2013).

\section{Análises discursivas}

Apresentamos a seguir recortes das entrevistas de quatro professores que discorreram sobre as práticas pedagógicas de leitura desenvolvidas em suas salas de aula.

Recorte 1 - “Ah, a leitura é muito importante, né? Amadurece, né? Amadurece a criança, né? Ela amplia o vocabulário dela, né? E... da condição dela produzir textos de conhecer... de conhecimento né, no geral... Aí porquê... pro mundo hoje né, precisa, né? (...) hoje em dia precisa, a vida exige né, esse conhecimento todo e mais tarde pra entrar no mercado de trabalho né..."

A análise desse recorte nos permite afirmar que esse sujeito se inscreve em formações discursivas que consideram a leitura importante para a vida dos alunos. Contudo, percebemos que essa importância está ligada a fins meramente utilitaristas e burocráticos da leitura, como por exemplo, amadurecimento da criança, ampliação do vocabulário e utilização para entrada no mercado de trabalho.

Pesquisadores como Biarnés (1998), Candido (2004), Assolini (2020); Tfouni (2005) defendem que o ensino da leitura deve se dar para além dos fins escolares, pois o ato de ler possui uma função social maior que a mera utilização na escola. O que observamos, porém, é que "a escola, por sua vez, estabelece a funcionalidade da relação com a letra como fundamento do sucesso individual e o acesso a valores como a autonomia e a necessária competição" (BIARNÉS, 1998, p. 143).

Concordamos com Biarnés (1998), quando este afirma que a escola cria uma relação de funcionalidade com a letra, amparando-se em princípios mercadológicos que geram no espaço escolar competições, responsabilização e meritocracia, valores esses incompatíveis com a função da instituição escolar de forma ampla, e com o ensino da leitura e da escrita, de forma particular.

Paro (1999, p. 1) dialogando com Biarnés (1998) afirma que essa lógica de preparar os alunos para o mercado de trabalho não deve ser o foco principal da escola uma vez que, "[...] os objetivos que se buscam na empresa capitalista não são apenas diferentes, mas antagônicos aos buscados na escola". Pensar na educação/leitura apenas como preparação para o mercado de trabalho é reduzir essa prática cultural, a leitura, à função menor, insignificante, descabida, pois aprender a ler permite-nos entender o mundo à nossa volta, adquirir conhecimentos, realizar descobertas, movimentarmo-nos por diferentes regiões de sentidos, atribuindo sentidos.

Defendemos o entendimento segundo o qual o ensino da leitura deve contribuir para que os estudantes aprendam que ler não é atividade neutra, e que os sentidos não são únicos, óbvios e transparentes.

A nosso ver, a literatura constitui-se em recurso privilegiado para o ensino da leitura e da escrita, nos anos iniciais do Ensino Fundamental. Concordamos com Candido (2004, p. 122) quando este afirma que a literatura "[...] corresponde a uma necessidade universal que deve ser satisfeita sob a pena de mutilar a personalidade, porque pelo fato de dar forma aos sentimentos e à visão do mundo ela nos organiza, nos liberta do caos e, portanto, nos humaniza". 
Outro aspecto observado durante as entrevistas é que as práticas pedagógicas de leitura são sempre organizadas seguindo o material didático, que é utilizado por toda a rede estadual paulista, como veremos nos recortes a seguir.

Recorte 2 - "É... a gente tem que dar duas vezes por semana a leitura de livros, aí a gente tem os livros, tem é... o... Gibis, pode dar leitura compartilhada também, que é aquela leitura que todo mundo vai ler um texto juntos, tudo de acordo com o Ler e Escrever"

No recorte número 2, o sujeito professor afirma que "tem que dar" leitura de livros duas vezes por semana. A presença da expressão verbal "tem que" mostra-nos que há regras sob as quais as práticas pedagógicas estão sujeitas. A expressão "tem que" produz um efeito de sentido de autoritarismo e prescrição, ou seja, o professor tem que encaixar-se nas normas previstas. Ao final do recorte percebemos que essas normas advêm do material didático oficial do Estado de São Paulo, denominado Ler e Escrever, pois estas práticas estão de acordo com as orientações contidas no material.

Os significantes "tem que dar" e "pode dar" (re)afirmam a submissão do professor a outras instâncias, este, deve então, ser apenas executor, seguindo orientações externas, e necessitando ser autorizado por instâncias superiores e legitimadas, como é o caso dos órgãos oficiais de ensino, que prescrevem o que e como deve ser ensinado. De acordo com Assolini (1999, p. 220-221) “[...] o professor segue resignadamente as orientações teóricas e metodológicas, apresentadas pelos autores dos livros didáticos nos manuais de instrução", com isso, agentes externos determinam a prática realizada nas salas de aula desses professores.

Essa desvalorização dos saberes e fazeres docentes, no contexto escolar, trazem impactos negativos para o ensino de leitura e, também, para as práticas pedagógicas escolares, de maneira ampla, uma vez que pressupõem um professor que, supostamente, não é capaz de realizar o seu ofício, a partir de seus próprios conhecimentos e saberes acumulados.

Durante nossas observações, percebemos que todas as práticas pedagógicas que dizem respeito à alfabetização, à leitura e à escrita são definidas pelo material didático enviado através do governo estadual, com isso, notamos que há uma formação imaginária a respeito do governo, como sendo um agente neutro, que faz as escolhas corretas, sem vinculá-las a uma ideologia e uma intencionalidade. Porém, de acordo com Pêcheux (2014a, p. 135) "só há prática através de e sob uma ideologia".

Para "fechar" a presente análise, ressaltamos que o que temos podido observar é que a escola "a mais importante agência de letramento", no dizer de Kleiman (1995), preocupa-se não com o letramento enquanto prática social, mas apenas com um tipo de prática de letramento: a alfabetização, que ora é concebida e trabalhada como processo de aquisição de códigos (alfabéticos, numéricos), ora como um processo de representação de objetos diversos de natureza diferentes.

Recorte 3 - No caso assim... a gente tem o material que o governo oferece, então os livros são próprios para aquela idade... aquela faixa etária... a gente tem a caixa e aí a gente fica livre pra poder utilizar o livro que a gente quer... aí no caso aqui como a gente é... por ano, cada ano trabalha um projeto diferente, então é... o segundo ano trabalha parlendas, cantigas, então eu vou ler muita parlenda, eu vou ler bastante cantigas é... vou ler no terceiro ano é bastante música, poemas, é... fábulas, então a gente consegue focar em tipo de texto, mas não que eles não conhecem os outros, eles conhecem todos, é que o material propõe dentro da atividade aquilo, mas a gente pode usar todos os textos...

No decorrer de seu relato o sujeito-professor afirma que "No caso assim... a gente tem o material que o governo oferece então os livros são próprios para aquela idade", através dessa SDR 
percebemos que o governo é quem "oferece" às escolas os livros que serão trabalhados em sala de aula. Esse direcionamento da leitura própria para cada idade é visto pelo professor como uma ação legitimada e correta, já que é oferecida por um agente externo e superior à escola, o governo.

Com isso, questionamo-nos quais são as relações que os professores e seus alunos constroem com a leitura, uma vez que os livros utilizados em sala de aula são determinados por agentes externos à escola. Tal forma de organizar o trabalho com a leitura acaba se dando de maneira compartimentada e sem sentido, uma vez que, pressupõe uma subdivisão de leitores por idade, não levando em consideração a particularidade e as preferências dos diferentes alunos que podem constituir uma mesma sala de aula.

Nesse recorte, podemos perceber também o trabalho de naturalização dos sentidos através da ideologia, na seguinte SDR: "a gente tem a caixa e aí a gente fica livre pra poder utilizar o livro que a gente quer". Esse sujeito professor está preso a uma ilusão de liberdade, onde não é capaz de perceber que a sua escolha é pré-determinada, ou seja, ele só pode escolher a partir das opções já oferecidas pelo governo. Portanto, não se trata de uma escolha própria, livre, de acordo com o desejo do professor, mas sim uma escolha a ser feita a partir do que é disponibilizado pela instituição governamental.

A naturalização de sentidos causada pelo trabalho da ideologia, nos remete a formações discursivas em que o sujeito professor desenvolve sua prática pedagógica amparada apenas na paráfrase, em outras palavras, a falta de autoria do professor é naturalizada, fazendo com que estes tenham a ilusão de que estão fazendo escolhas livres e de acordo com a sua própria vontade.

Outro aspecto que podemos observar nesse recorte, é o fato de que a leitura é vista como uma atividade que visa apenas cumprir funções curriculares, uma vez que, em cada ano são trabalhados gêneros textuais específicos pré-determinados pelo currículo. A esse respeito, fica-nos evidente na SDR: "o segundo ano trabalha parlendas, cantigas, então eu vou ler muita parlenda, eu vou ler bastante cantigas é... vou ler no terceiro ano é bastante música, poemas, é... fábulas".

Sendo assim, a leitura se destitui de seu aspecto prazeroso, de fruição, e apresenta-se de maneira secionada, onde a aprendizagem dos alunos se dá através da delimitação e segmentação proposta pelos órgãos governamentais. Nesse sentido, corroboramos com Assolini (2008, p. 91) quando a pesquisadora afirma que "o deslocamento de sentidos prefixados e a produção de novos requerem que o DPE acolha a compreensão de que um trabalho com a leitura precisa considerar a relação entre o simbólico e as relações de poder".

Encerrando as análises desse recorte temos a última SDR: "é que o material propõe dentro da atividade aquilo, mas a gente pode usar todos os textos". Através dessa sequência discursiva, é possível perceber que o MD é considerado como o detentor do conhecimento único e confiável. Com isso, a leitura se torna uma "[...] ferramenta, cuja utilização cotidiana em sala de aula instrumentaliza a mesmice, a padronização e a formação de um sujeito repetidor, capaz apenas de observar sentidos literais" (ROMÃO; PACÍFICO, 2006, p. 17).

Dando sequência, vamos nos concentrar no próximo recorte.

Recorte 4 - A leitura, oh... todos os dias é a leitura pelo professor, uma vez por semana tem a roda de leitura, que é onde que as crianças levam o livro pra casa, aí eles, por exemplo, eles levaro, por exemplo, essa semana que passou eu dei um livro igual para todos eles, aí nessa roda de leitura você pode... a gente vai 'e que que falou do livro? Quem era o autor? quem não era, que que eles gostaram mais, qual página que eles mais gostaram, qual o autor... qual o personagem que eles mais gostaram' [...] vamo fazer umas perguntas pra eles pra ver se eles entenderam, né? 
Nesse recorte, o sujeito afirma que há leitura pelo professor todos os dias e que uma vez por semana há uma roda de leitura. Conforme a professora vai explicando como se dá o trabalho com a leitura, percebemos que há algumas determinações sobre o trabalho com a leitura, com isso

[...] as formações discursivas nas quais a escola permite que os alunos se insira não são quaisquer; são antes estabelecidas por formações ideológicas que atribuem um modo de funcionamento à instituição escolar que faz parecer que se está fazendo o melhor para homogeneizar e igualar aqueles que são diferentes e heterogêneos (TFOUNI, 1996, p. 17).

Seguindo em sua resposta, a professora exemplifica como a roda de leitura é trabalhada em sala de aula: "que que falou do livro? Quem era o autor? quem não era, que que eles gostaram mais, qual página que eles mais gostaram, qual o autor”. Essa maneira de trabalhar utiliza-se de perguntas que levam à paráfrase, ao já dado, enquanto a polissemia e a criação de sentidos ficam sem espaço em sala de aula.

O fato de o ensino da leitura estar sustentado pela ilusão de sentido literal ou do efeito referencial traz como consequência o entendimento de que compreender o texto significa simplesmente ir ao código linguístico e buscar "o" sentido que estaria colado à palavra.

De acordo com Romão e Pacífico (2006, p. 17) essas perguntas de entendimento do texto “[...] constroem uma grande rede de receitas semiprontas, experimentação de um processo de gramaticalização do texto e da leitura e, assim, contribuem para a diminuição do prazer de trabalhar com a linguagem". Nessas condições de produção, raramente o estudante ocupará o lugar de intérprete-historicizado, lugar fundamental para que possa se tornar autor de seu próprio dizer, segundo Assolini (2020).

Desta forma, a leitura é vista enquanto decodificação, e a única descoberta possível é dos sentidos que já estão nas palavras. Assim sendo, as formações discursivas a que esse sujeito se filia é a que considera a prática de leitura enquanto decodificação, formação discursiva essa que abarca todos os sujeitos professores até aqui apresentados.

Entendemos que um fazer pedagógico que valoriza a importância e a complexidade do ato de ler deve criar "[...] espaços interpretativos, o que possibilitaria aos alunos inscrevem-se no interdiscurso, criarem sítios de significância e, portanto, historicizarem os sentidos, colocando-os ativos no funcionamento da linguagem" (ASSOLINI, 2008, p. 93).

Encerrando as análises, notamos que os professores são assujeitados e se submetem ao entendimento segundo o qual haveria um único sentido possível para a leitura, como sendo uma prática que busca "ouvir" os sentidos do texto presente pelas palavras do autor, que, por sua vez, são únicos, estáveis e transparentes. Esse efeito da ideologia traz ao sujeito a evidência de que a leitura é assim, e não poderia ser de outra forma. Assim sendo, o sujeito professor é visto como um mero aplicador das orientações do material didático, sobretudo porque não se entende como um profissional capaz de refutar e de contrapor-se ao que lhe é imposto e romper com o imaginário que o discursiviza como um profissional de pouco valor.

\section{Considerações finais}

Nossas análises apontam que o processo de alfabetização se dá em condições de produção onde a leitura é pautada na paráfrase, excluindo as possibilidades polissêmicas. Assim sendo, a leitura não acontece como criação de sentidos, mas sim, como uma prática que leva os alunos a admitirem que os sentidos do texto são somente aqueles legitimados e não outros. 
Essa maneira de ensinar a ler nas escolas, muitas vezes, não faz sentido(s) para o aluno, e se essa prática não interfere positivamente em sua vida, por que ele vai continuar lendo? Qual o sentido de ler se isso não lhe possibilita criar, imaginar, fruir, voar e duvidar dos sentidos ali colocados? Consideramos que "Ler é haver-se com a letra, seus desvios, labirintos, atalhos. Ler é se confrontar com o impensado, com o simbólico, com o sentido em devir. É um risco" (FEDATTO, 2016, p. 85).

Entendemos assim, que o ensino da leitura através da perspectiva discursiva do letramento possibilitaria aos educandos questionar os sentidos legitimados no espaço escolar e criar novas interpretações, com isso, a leitura passaria a ter mais sentido e também, uma função social na vida dos alunos.

\section{Referências}

ASSOLINI, F. E. P. Estudantes não alfabetizados no ensino fundamental: da exclusão à produção de sentidos. Brasilian Journal of Development, v. 7, p. 553-561, 2021. DOI: https://doi.org/10.34117/bjdv7n1-038. Acesso em: 26 out. 2021.

ASSOLINI, F. E. P. Professores e suas relações com a leitura e a escrita: ecos para suas práticas pedagógicas. Jundiaí: Paco, 2020.

ASSOLINI, F. E. P. A escrita e sujeitos-professores: relações, cicatrizes, ensino e identidade profissionais. In: PAYER, M. O.; CELADA, M. T. (Org.). Subjetivação e processos de identificação: sujeitos e línguas em práticas discursivas - inflexões no ensino. Campinas: Fontes Editores, 2016. p. 125-146.

ASSOLINI, F. E. P. Alfabetização e letramento: aspectos históricos, conceituais e proposta pedagógica. In: MORENO, L. C. (Org.). Educação: uma visão (da ARE). Ribeirão Preto: Legis Summa, 2015. p. 67-90.

ASSOLINI, F. E. P. Análise discursiva dos saberes e fazeres pedagógicos de professores do ensino fundamental. Alfa, São Paulo, v. 52, n. 1, p. 123-147, 2008.

ASSOLINI, F. E. P. Interpretação e letramento: os pilares de sustentação da autoria. 2003. 269f. Tese (Doutorado em Psicologia) - Departamento de Psicologia e Educação, Faculdade de Filosofia, Ciências e Letras de Ribeirão Preto, Universidade de São Paulo, Ribeirão Preto, 2003.

ASSOLINI, F. E. P. Pedagogia da leitura parafrástica. 1999. 233f. Dissertação (Mestrado em Psicologia) - Departamento de Psicologia e Educação, Faculdade de Filosofia, Ciências e Letras de Ribeirão Preto, Universidade de São Paulo, Ribeirão Preto, 1999.

BIARNÉS, J. O ser e as letras: da voz à letra, um caminho que construímos todos. Rev. Fac. Educ., São Paulo. Trad. I. Mantoanelli. v. 24, n. 2, [n. p.], jul. 1998. DOI: https://doi.org/10.1590/S0102-25551998000200009. Acesso em: 26 out. 2021.

CANDIDO, A. O direito à literatura. In: CANDIDO, A. Vários escritos. São Paulo: Duas Cidades; Rio: Ouro sobre Azul, 2004. p. 169-191.

COURTINE, J. J. Definição de orientações teóricas e construção de procedimentos em análise do discurso. Policromias. Trad.: F. C. Souza e M. L. A. Silva, ano 1, p. 14-35, jun. 2016. 
Disponível em: https://revistas.ufrj.br/index.php/policromias/article/view/4090/3058. Acesso em: 17 jun. 2021.

COURTINE, J. J. Definition d'orientations théoriques et construction de procédures en analyse du discours. Philosophiques, v. 9, p. 239-264, 1982.

FEDATTO, C. P. O que diz ao negar-se a ler? In: PAYER, M. O.; CELADA, M. T. (Org.). Subjetivação e processos de identificação: sujeitos e línguas em práticas discursivas-inflexões no ensino. Campinas: Pontes Editores, 2016. p. 79-94.

FERNANDES, C. A. Análise do discurso: reflexões introdutórias. São Carlos: Claraluz, 2008.

FERNANDES, C. As várias brancas de Rosinha: uma prática de leitura para a assunção da autoria. In: ASSOlINI, F. E. P.; PIMENTA, L. A.; DORNELAS, C. C. (Org.). (Entre)laçamentos discursivos: docência e práticas pedagógicas. Curitiba: CRV, 2018. p. 29-42.

GINZBURG, C. Sinais: raízes de um paradigma indiciário. In: GINZBURG, C. Mitos, emblemas, sinais: morfologia e história. Trad. F. Carotti. São Paulo: Companhia de Letras, 1989. p. 143-179.

GREGOLIN, M. R. V. Michel Pêcheux e a história epistemológica da linguística. Estudos da Língua(gem), Vitória da Conquista, n. 1, p. 99-11, 2005.

KLEIMAN, A. B. Os significados do letramento: uma nova perspectiva sobre a prática social da escrita. Campinas: Mercado de Letras, 1995.

ORLANDI. E. P. A linguagem e seu funcionamento: as formas do discurso. Campinas: Pontes, 2011.

ORLANDI. E. P. Análise de discurso: princípios e procedimentos. 8 ed. Campinas: Pontes, 2009.

ORLANDI. E. P. Interpretação e autoria: leitura e efeitos do trabalho simbólico. Rio de Janeiro: Vozes, 2007.

ORLANDI. E. P. Discurso e leitura. 6 ed. São Paulo: Cortez; Campinas: Ed. Unicamp, 2001.

PARO, V. H. Parem de preparar para o trabalho!!! reflexões acerca dos efeitos do neoliberalismo sobre a gestão e o papel da escola básica. In: FERRETTI, C. J. (Org.). Trabalho, formação e currículo: para onde vai a escola. São Paulo, Xamã, 1999. p. 101-120.

PAULA, F. S.; TFOUNI, L. V. Regularidade e acontecimento no funcionamento do discurso pedagógico escolar. SIGNUM: Estud. Ling., Londrina, n. 16, v. 2, p. 193-213, dez. 2013.

PÊCHEUX, M. Semântica e discurso: uma crítica à afirmação do óbvio. Trad. E. P. Orlandi et al. 2 ed. Campinas: Ed. da Unicamp, 2014a.

PÊCHEUX, M. Análise automática do discurso. In: GADET, F; HAK, T. (Org.). Por uma análise automática do discurso. 4 ed. Campinas: Ed. da Unicamp, 2014b. p. 59-158. 
ROMÃO, L. M. S.; PACÍFICO, S. M. R. Era uma vez uma outra história: leitura e interpretação na sala de aula. São Paulo: DCL; 2006.

TFOUNI, L. V. Letramento e autoria - uma proposta para contornar a questão da dicotomia oral / escrito. Revista ANPOLL, n. 18, p. 127-141, jan./jun. 2005.

TFOUNI, L. V. Letramento e alfabetização. São Paulo: Cortez, 1996.

TFOUNI, L. V.; PEREIRA, A. C.; ASSOLINI, F. E. P. Letramento e alfabetização e o cotidiano: vozes dispersas, caminhos alternativos. Unisinos, v. 16, n. 1, p. 16-24, jan./abr. 2018.

\section{Sobre as autoras}

Letícia Moraes Esposto. Mestranda em Educação pela Faculdade de Filosofia Ciências e Letras de Ribeirão Preto-USP. Possui especialização em BNCC pelo Centro Universitário Claretiano de Batatais. Pedagoga licenciada pela Faculdade de Filosofia Ciências e Letras de Ribeirão PretoUSP. Foi bolsista de Iniciação Científica com bolsa FAPESP. Membro pesquisador e vice-líder do grupo de estudos e pesquisas GEPALLE - Grupo de Estudos e Pesquisas sobre Alfabetização, Leitura e Letramento da Faculdade de Filosofia, Ciências e Letras de Ribeirão Preto, desde 2015. Experiência na área de educação, tendo também participações e organização de atividades e eventos científicos, extensão universitária, projetos de pesquisa e estágios curriculares.

E-mail: leticiaesposto@gmail.com.

Filomena Elaine Paiva Assolini. Possui graduação em Letras - Instituição Moura Lacerda (1992), graduação em Pedagogia - Instituição Moura Lacerda (1987), mestrado em Psicologia pela Faculdade de Filosofia Ciências e Letras de Ribeirão Preto USP (1999) e doutorado em Ciências pela Faculdade de Filosofia Ciências e Letras de Ribeirão Preto USP (2003). Concluiu o Pós-Doutorado no Instituto de Estudos da Linguagem, IEL-UNICAMP. É docente da FFCLRP-USP desde 2005. Atua na interface Educação e Linguística, desenvolvendo pesquisas sobre alfabetização, letramento, leitura, escrita, formação de professores e prática pedagógica escolar. Atualmente é professora Livre-docente da Faculdade de Filosofia Ciências e Letras de Ribeirão Preto-USP; membro titular da Comissão do Curso de Pedagogia; membro da Comissão de Monografia da Faculdade de Filosofia Ciências e Letras de Ribeirão Preto, membro do Conselho do Departamento-DEDIC. Ministra disciplinas regulares e optativas na graduação e na pós-graduação em Educação. Desenvolve pesquisas relacionadas à interface Educação e Linguística e orienta estudantes de iniciação científica, mestrado e doutorado. É responsável por vários projetos de cultura e extensão universitária, com destaque para a Incubadora Cultural. É líder e coordenadora do Grupo de Estudos e Pesquisas Sobre Alfabetização, Leitura e Letramento, GEPALLE, regulamentado no CNPq.

E-mail: elainefdoc@ffclrp.usp.br. 